\title{
Työterveyshoitajien näkemys työpaikkakulttuurista
}

\begin{abstract}
Abstrakti
ysh Tutkimuksen tarkoituksena on kuvata työterveyshoitajien näkemystä työterveyshuollon työpaikkakulttuurista. Tutkimusaineisto kerättiin sähköisellä kyselylomakkeella. Vastaajina olivat työikäiset työterveyshoitajat $(n=187)$. Kyselylomake sisälsi taustatiedot-osion sekä The Nursing Context Index ja The Affective Commitment Scale -mittarit. Mittarit muodostuivat väittämistä, joihin samaistumista työterveyshoitajat arvioivat seitsemänportaisella Likert-asteikolla. Aineisto analysoitiin tilastollisin menetelmin. Työterveyshoitajat kokivat työpaikkakulttuurinsa kokonaisuudessaan lievästi myönteiseksi. Stressiä koettiin jonkin verran, työmäärä oli suurin stressin aiheuttaja. Työhönsä työterveyshoitajat olivat melko tyytyväisiä. Kaikkein tyytyväisimpiä oltiin työhön henkilökohtaisella tasolla, tyytymättömimpiä palkkaan ja mahdollisuuksiin. Työympäristö koettiin jokseenkin myönteisenä. Parhaiten työympäristössä koettiin toteutuvan lääkäri-hoitaja-yhteistyö, heikoimmaksi koettiin henkilökunnan ja muiden resurssien riittävyys. Työterveyshoitajat, joilla on työterveysasiakkaita 901-1200, sekä työterveyshoitajat, joilla on työkokemusta nykyisessä työpaikassa 5-15 vuotta, erottuvat muista ollen laaja-alaisesti stressaantuneimpia, tyytymättömimpiä työhönsä sekä suhtautumalla hieman muita kielteisemmin työympäristöönsä. Näille työterveyshoitajille johtajien tulee erityisesti kohdentaa tukitoimintoja.
\end{abstract}

\section{Johdanto}

Terveydenhuolto on Suomessa muutosten edessä. Työterveyshuollossa on koko 2000-luvun ajan ollut käynnissä voimakas rakennemuutos: palveluntuottajien määrä on vähentynyt aiemmasta ja työterveysyksiköiden koko on kasvanut. Kunnallisia työterveysyksiköitä on yhdistynyt liikelaitoksiksi, työnantajien omia työterveysyksiköitä on ulkoistettu ja yksityiset terveyskeskuksen lääkäriasemaketjut ovat ostaneet ja integroineet pienempiä lääkäriasemia. Vuoden 2015 lopussa Suomessa toimi 406 työterveysyksikköä, joissa terveydenhoitajan toimia oli 2210. Henkilöasiakkaita työterveyshoitajilla oli keskimäärin 784 (mediaani), vaih- dellen terveyskeskuksen 787 (mediaani) henkilöasiakkaan, lääkärikeskuksen 863 (mediaani) ja yrityksen oman työterveysyksikön 543 (mediaani) henkilöasiakkaan välillä. Henkilöasiakkaiden määrä työterveyshoitajaa kohden on noussut, mutta muusta työterveyshenkilöstöstä poiketen terveydenhoitajien toimien määrä työterveyshuollossa ei ole muuttunut merkitsevästi viimeisen 10 vuoden aikana. (Lappalainen ym. 2016.) Vuonna 2015 työterveyshuollon piirissä oli 1,8 miljoonaa työntekijää. Tuona vuonna työterveyshuollon piiriin kuuluvista työntekijöistä 60 prosenttia sai työterveyshuollon palvelut yksityiseltä lääkäriasemalta, 23 prosenttia kunnallisista terveyskeskuksista tai liikelaitoksista, 9 prosenttia työnanta- 
jan omalta työterveysasemalta, 6 prosenttia työnantajien yhdessä omistamilta työterveysasemilta ja loput prosenttiosuudet muilta palveluntuottajilta (Kela 2017).

Terveydenhuoltohenkilöstön ikääntyminen, eläköityminen ja siirtyminen hoitotyöstä muille aloille asettavat rajoituksia työvoiman tarjonnalle. Siksi on tärkeää tunnistaa tekijät, jotka saavat hoitajat lähtemään työstään sekä löytää ne tekijät, jotka edesauttavat hoitajien työssä pysymistä ja työhön sitoutumista (Lu ym. 2012; Chan ym. 2013). Työpaikkakulttuurin on todettu olevan yhteydessä työntekijöiden työhön sitoutumiseen sekä työntekijöiden vaihtuvuuteen (Glisson \& James 2002).

Erityisesti affektiivisen, tunneperäisen sitoutumisen tiedetään lisäävän työtyytyväisyyttä ja vähentävän henkilöstön irtisanoutumista. Affektiivisesti sitoutunut työntekijä on tunneperäisesti kiinnittynyt organisaatioon. Hän kokee yhteenkuuluvuuden tunnetta organisaation kanssa sekä jakaa sen arvot ja tavoitteet. Affektiivisesti sitoutunut työntekijä jatkaa työskentelyä organisaatiossa, koska itse niin haluaa. Affektiivista sitoutumista pidetään merkittävimpänä työntekijän työpaikkakäyttäytymiseen vaikuttavana sitoutumisen ulottuvuutena. Sen on todettu olevan positiivisessa yhteydessä työtyytyväisyyteen, työhyvinvointiin sekä työn ja perheen yhteensovittamiseen. (Allen \& Meyer 1990; Meyer ym. 2002.) Työpaikkakulttuurin laajalle ulottuvien vaikutusten vuoksi sen tutkiminen on tärkeää. Suomessa työpaikkakulttuuria on aiemmin tutkittu useissa eri hoitotyön konteksteissa, esimerkiksi perusterveydenhuollossa (Hahtela 2015), terveysasemalla (Sannemann ym. 2017) ja psykiatrisessa hoitotyössä (Kurjenluoma ym. 2017). Työterveyshuollon kontekstissa työpaikkakulttuuria ei ole kuitenkaan aiemmin tutkittu. Myös kansainvälistä tutkimusta työpaikkakulttuurista tai sen osaalueista, eli stressistä, työtyytyväisyydestä ja työympäristöstä, työterveyshoitajien kokemana on huonosti saatavilla.

\section{Tutkimuksen teoreettiset lähtökohdat}

Kulttuuri on työyhteisössä vahva, piilevä ja useimmiten tiedostamaton rakenne, joka määrittää työyhteisön jäsenten arvomaailmaa ja käyttäytymistä (Schein 2010). Kulttuuri luo työyhteisöön yhtenäisyyttä antaen sille säännöt ja rakenteet, joiden mukaan toimia. Jokaisella organisaatiolla ja sen jokaisella työyksiköllä on oma ainutlaatuinen kulttuurinsa. Kulttuuri vaikuttaa palveluiden laatuun, henkilöstön palveluasenteeseen sekä annetun hoidon tuloksiin. (Hemmelgarn ym. 2006.)

Työpaikkakulttuuri on työyhteisössä vallitseva kulttuuri, joka määrittää ja säätelee työyhteisöön kuuluvien ajattelu- ja toimintatapaa. Se on kulttuuri, jonka työyhteisössä työskentelevät ja siellä asioivat kokevat päivittäin. (Manley ym. 2011.) Työpaikkakulttuuri ja organisaatiokulttuuri vaikuttavat toinen toisiinsa. Työpaikkakulttuuriin vaikuttaa myös konteksti, jossa kyseinen organisaatio toimii. (Hemmelgarn ym. 2006.) Työpaikkakulttuurilla on merkitystä niin potilaiden, hoitohenkilökunnan kuin organisaationkin näkökulmasta. Sillä on yhteys yksilöiden ja tiimien käyttäytymiseen, työtyytyväisyyteen, potilaiden hoitoon ja organisaation menestykseen (Hahtela 2015) sekä työhön sitoutumiseen ja työntekijöiden vaihtuvuuteen (Glisson \& James 2002). Työpaikkakulttuurin on todettu olevan yhteydessä myös hoitajien sairauspoissaoloihin, ylitöihin ja työtapaturmiin (Hahtela 2015). Työpaikkakulttuuria voidaan tarkastella työntekijän kokeman stressin, työtyytyväisyyden ja työympäristön näkökulmasta (Slater \& McCormack 2006).

Työterveyshoitajat kokevat, että työ on ajoittain vaativaa ja uuvuttavaa. Työnantajien ja työntekijöiden arvostus työtä kohtaan on vähäistä. (Naumanen-Tuomela 2001.) Työn jatkuva muuttuminen sekä työelämän uusiin vaatimuksiin sopeutuminen ovat keskeisiä haasteita ja stressitekijöitä työterveyshoitajan työssä. Ne myös vaikuttavat työterveyshoitajan hyvinvointiin ja työssä jaksamiseen. 
(Kyrönlahti 2005.) Työterveysyksiköiden koko henkilöstöä koskevassa tutkimuksessa asiakasmäärien lisääntymisen todettiin lisäävän henkilöstön työstressiä ja heikentävän heidän työ- ja perhe-elämänsä tasapainoa. Eniten stressiä työterveyshenkilöstölle aiheuttivat tilanteet, joissa työntekijä koki asetetut vaatimukset kohtuuttomiksi ja liian suuriksi. (Moses ym. 2016.)

Kansainvälisessä tutkimuksessa on todettu työterveyshuollon henkilöstön olevan hyvin tyytyväisiä omaan työhönsä ja omaan elämäänsä. Työtyytyväisyyttä lisäävät työn mielekkyys, itsenäisyys ja organisaatiolta saatu tuki. (Moses ym. 2016.) Myös Sakowskin (2012) mukaan työterveyshoitajat ovat tyytyväisiä työhönsä, vaikka täysin tyytyväisiä työhönsä työterveyshoitajista oli vain neljäsosa. Tyytyväisimpiä työterveyshoitajat olivat tehtäviensä vastuullisuuteen, yhteistoimintaan asiakkaiden kanssa, yhteistyöhön työterveyslääkärien kanssa ja tehtäväkentän laajuuteen. Curtisin ja Glackenin (2014) tutkimuksessa terveydenhoitajat olivat tyytyväisimpiä omaan ammattiasemaansa, vuorovaikutukseen ja työn autonomiaan. Vähiten tyytyväisiä he ovat ammatillisiin etenemismahdollisuuksiinsa ja palkkaukseen (Sakowski 2012). Terveydenhoitajiin kohdistuvassa tutkimuksessa hoitajien ammattiasemalla, vuorovaikutuksella ja työn autonomialla oli suurin kontribuutio terveydenhoitajien työtyytyväisyyteen. (Curtis \& Glacken 2014.)

Työterveysyksikön toimivuus edistää työntekijöiden henkistä hyvinvointia ja vaikuttaa myönteisesti yksikön tulokselliseen toimintaan (Simola 2001). Työympäristössään työterveyshoitajat ovat kokonaisuudessaan melko tyytyväisiä yhteistyöhön työterveyslääkärien kanssa. Toisaalta useampi kuin yksi kymmenestä kokee tyytymättömyyttä lääkärihoitaja-yhteistyössä. (Sakowski 2012.) Työterveysyksikön koko henkilöstöä koskevassa tutkimuksessa työntekijöiden aikeet vaihtaa työpaikkaa olivat suhteellisen matalat ja aikeet vaihtaa pois työterveyshuollosta vielä matalammat (Moses ym. 2016).
Myönteisen organisaatio- ja työpaikkakulttuurin edistäminen on tärkeä tavoite, sillä myönteiseksi kulttuurinsa kokevat ovat muita ylpeämpiä työstään. He ovat myös muita sitoutuneempia organisaatioon. Myönteisessä kulttuurissa työntekijät kokevat saavansa kunnioitusta ja kestävät siten paremmin työnsä haasteellisuutta sekä siitä aiheutuvaa stressiä. (Shirey 2009.) Organisaatioon sitoutuminen on ominaista erityisesti vanhemmille työntekijöille ja pidempään organisaatiossa työssä olleille (Ruokolainen 2011; Miedaner ym. 2018). Sitoutuminen ilmenee työntekijän voimakkaana vastuuntuntona ja työn keskeisenä merkityksenä työntekijän elämässä (Ruokolainen 2011). Isoissa organisaatioissa tai suuremmissa yksiköissä yksittäisten hoitajien sitoutuminen ei ole niin voimakasta kuin pienemmissä. Pienemmässä organisaatiossa hoitajan on helpompi tuntea organisaatio ja tunnistaa oma roolinsa osana organisaatiota, mikä helpottaa hoitajan organisaatioon samaistumista. (Miedaner ym. 2018). Sitoutuminen organisaatioon lisää henkilöstön tehokkuutta ja suorituskykyä työssä. Affektiivisesti sitoutuneet hoitajat kokevat myös vähemmän stressiä työssään ja ovat epätodennäköisemmin vaihtamassa työpaikkaa. (Meyer ym. 2002; Turunen 2012.) Työyhteisössä saatu sosiaalinen tuki ja autonomia lisäävät organisaatiositoutumista (Miedaner ym. 2018). Työterveyshuollon henkilöstön organisaatioon sitoutumista vahvistaa työntekijän esimieheltä ja organisaatiolta saama arvostus. Myös työntekijän ja organisaation arvomaailmojen yhteensopivuus lisää sitoutumista. (Simola 2001.)

\section{Tutkimuksen tarkoitus, tavoite ja tutkimuskysymykset}

Tutkimuksen tarkoituksena on kuvata työterveyshuollon työpaikkakulttuuria työterveyshoitajien näkökulmasta. Tavoitteena on tuottaa tietoa, jota voidaan hyödyntää työterveyshuollon työpaikkakulttuuria kehitettäessä. Tämän artikkelin tutkimuskysymykset ovat: 
1. Millainen on työterveyshuollon työpaikkakulttuuri työterveyshoitajien kokemana?

2. Miten työterveyshoitajien kokemus affektiivisesta sitoutumisesta on yhteydessä työterveyshuollon työpaikkakulttuuriin?

\section{Tutkimuksen toteuttaminen ja menetelmät}

Tutkimuksen kohderyhmänä olivat työterveyshoitajat. Tutkimusaineisto kerättiin sähköisellä kyselylomakkeella keväällä 2018. Tutkimukseen ei liittynyt erityisiä eettisiä kysymyksiä. Tutkimushankkeen johtajalla oli lupa käyttää aikaisemmissa tutkimuksissa (esim. Cohen 1996; Slater ym. 2009) luotettaviksi todettuja mittareita. Vastaaminen kyselylomakkeeseen tulkittiin tutkittavien suostumukseksi osallistua tutkimukseen. (TENK 2012.) Ammattiliiton yhteyshenkilö lähetti saatekirjeen linkkeineen sähköpostitse kaikille liiton jäsenenä oleville työikäisille työterveyshoitajille ( $\mathrm{N}=1227)$. Vastausaikaa oli kuukausi. Muistutuskirjeitä lähettiin kolme. Kyselylomakkeita palautui 197. Näistä hylättiin 10, koska ne olivat tyhjiä, keskeneräisiä tai vastaaja ei työskennellyt työterveyshuollossa. Tutkimukseen hyväksyttiin 187 vastaajan vastaukset.

Kyselylomake sisälsi taustamuuttujia (taulukko 1), työpaikkakulttuuria ja affektiivista sitoutumista organisaatioon mittaavat osiot. Työterveyshoitajat arvioivat työpaikkakulttuuriaan Slaterin ja McCormackin (2006) kehittämällä The Nursing Context Index (NCI) -mittarilla. Mittari rakentuu kolmesta ulottuvuudesta: stressistä, työtyytyväisyydestä ja työympäristöstä. Mittari sisältää 78 väittämää, joista 36 mittaa stressitekijöitä, 18 työtyytyväisyyteen ja 24 työympäristöön liittyviä tekijöitä (taulukko 2). Työterveyshoitajat arvioivat affektiivista sitoutumista kuusi väittämää sisältävällä The Affective Commitment Scale (ACS) -mittarilla (Meyer ym. 1993; Meyer ym.
2004). Mittareiden väittämiin työterveyshoitajat vastasivat seitsenportaisella Likertasteikolla.

Tutkimuksen aineisto analysoitiin käyttäen tilastollista SPSS 25.0 for Windows -ohjelmaa. Työpaikkakulttuuria kuvaavista väittämistä muodostettiin NCI-mittarin käyttöohjeiden mukaisesti 22 summamuuttujaa. Affektiivista sitoutumista mittaavista kuudesta väittämästä muodostettiin summamuuttuja ACS-mittarin käyttöohjeiden mukaisesti. Kaikki 23 summamuuttujaa muodostettiin laskemalla väittämien saamat arvot yhteen ja jakamalla summapistemäärä väittämien lukumäärällä. Muodostettujen summamuuttujien sisäinen johdonmukaisuus tarkastettiin.

Summamuuttujien jakaumat arvioitiin tarkastelemalla niiden histogrammeja ja vinoutta sekä testattiin Kolmogorov-Smirnov -testillä. Taustamuuttujien ja työpaikkakulttuurin yhteyttä tutkittiin yksisuuntaisella varianssianalyysillä (Anova), Kruskall-Wallis H-testillä tai Mann-Whitney U-testillä riippuen tarkasteltavana olevan muuttujan luokkien määrästä. Useampiluokkaisten ryhmien välistä eroa tarkasteltiin parivertailuilla (Bonferronin korjaus). Tulosten vertailtavuuden vuoksi päädyttiin kuvaamaan kaikkia mediaanein ja kvartiilein. Parivertailuista päädyttiin kuvaamaan p-arvot ja ryhmien väliset suunnat niissä kohdin kuin parivertailu osoitti tilastollisesti merkitseviä eroja.

Työpaikkakulttuurin ja affektiivisen sitoutumisen välistä yhteyttä tarkasteltiin Pearsonin korrelaatiokertoimella tai Spearmanin järjestyskorrelaatiokertoimella. Korrelaatiota tulkittiin seuraavasti: voimakas korrelaatio $(\mathrm{r}> \pm 0.5)$, kohtalaisen voimakas $( \pm 0.3 \leq$ $r \leq \pm 0.5)$ ja heikko korrelaatio $(r< \pm 0.3)$. Tilastollisesi merkitsevänä arvona pidettiin arvoa $\mathrm{p}<0.05$ ja tilastollisesti erittäin merkitsevänä arvoa p < 0.001. (Burns \& Grove 1997.) 


\section{Tutkimustulokset}

\section{Tutkimukseen osallistuneet}

Työterveyshoitajien keskimääräinen ikä oli 53 vuotta $\left(Q_{1}=45, Q_{3}=58\right)$. Vastaajista lähes kaikki (98\%) olivat naisia. Puolet vastaajista oli koulutustaustaltaan opistotasoisen koulutuksen ja kolmannes ammattikorkeakoulutuksen suorittaneita. Lähes kaikki vastaajat (96\%) olivat suorittaneet työterveyshoitajan pätevöittävän koulutuksen. (Taulukko 1.)

Terveydenhuollon ammatissa vastaajat olivat työskennelleet keskimäärin 25 vuotta $\left(Q_{1}=18, Q_{3}=33\right)$, josta nykyisessä työpaikassaan keskimäärin kahdeksan vuotta $\left(Q_{1}=3\right.$, $\mathrm{Q}_{3}=14$ ). Työterveyshoitajana työterveyshuollossa vastaajat olivat työskennelleet keskimäärin 17 vuotta $\left(Q_{1}=10, Q_{3}=23\right)$. Vastaajista lähes kaikki olivat vakinaisessa työsuhteessa. Hieman yli puolet työskenteli yksityisellä työnantajalla. Työterveysasiakkaita vastaajilla oli keskimäärin $900\left(Q_{1}=600, Q_{3}=1200\right)$. (Taulukko 1.)

\section{Työterveyshoitajien kokemukset työpaikkakulttuurista}

Työterveyshoitajat kokivat työpaikkakulttuurin työterveyshuollossa kokonaisuudessaan lievästi myönteisenä. Stressiä työterveyshoitajat kokivat jonkin verran $(\mathrm{md}=2.8)$. Suurin stressin aiheuttaja työterveyshoitajille oli työmäärä. Vähiten stressiä aiheuttavaksi koettiin ristiriidat toisten hoitajien kanssa ja hoitoon liittyvä epävarmuus. (Taulukko 2.)

Työhönsä työterveyshoitajat olivat melko tyytyväisiä (md=4.6). Kaikkein tyytyväisimpiä työterveyshoitajat olivat työhönsä henkilökohtaisella tasolla, tyytymättömimpiä palkkaan ja mahdollisuuksiin (esim. ylennyksiin, koulutuksiin osallistuminen). (Taulukko 2.)

Työympäristönsä työterveyshoitajat kokivat jokseenkin myönteisenä $(\mathrm{md}=4.5)$.
Taulukko 1. Työterveyshoitajien taustatiedot

\begin{tabular}{|c|c|c|}
\hline Taustamuuttuja & $\mathbf{n}$ & $\%$ \\
\hline \multicolumn{3}{|l|}{ lkä vuosissa } \\
\hline $28-45$ & 43 & 26 \\
\hline $46-55$ & 60 & 36 \\
\hline $56-65$ & 62 & 38 \\
\hline \multicolumn{3}{|l|}{ Korkein koulutus } \\
\hline terveydenhoitaja (opistotaso) & 94 & 50 \\
\hline terveydenhoitaja (amk) & 62 & 33 \\
\hline terveydenhoitaja (yamk) & 13 & 7 \\
\hline alempi yliopistotutkinto (kandidaatti) & 3 & 2 \\
\hline ylempi yliopistotutkinto (maisteri) & 15 & 8 \\
\hline \multicolumn{3}{|l|}{ Työterveyshuollon pätevöittävä koulutus } \\
\hline suoritettu & 181 & 96 \\
\hline suorittaa parhaillaan & 3 & 2 \\
\hline ei ole suorittanut & 3 & 2 \\
\hline \multicolumn{3}{|l|}{$\begin{array}{l}\text { Työkokemus terveydenhuollon } \\
\text { ammatissa }\end{array}$} \\
\hline alle 15 vuotta & 31 & 17 \\
\hline $15-25$ vuotta & 68 & 36 \\
\hline yli 25 vuotta & 88 & 47 \\
\hline \multicolumn{3}{|l|}{ Työkokemus nykyisessä työpaikassa } \\
\hline alle 5 vuotta & 54 & 31 \\
\hline 5-15 vuotta & 88 & 51 \\
\hline yli 15 vuotta & 31 & 18 \\
\hline \multicolumn{3}{|l|}{$\begin{array}{l}\text { Työkokemus työterveyshoitajana } \\
\text { työterveyshuollossa }\end{array}$} \\
\hline alle 15 vuotta & 69 & 38 \\
\hline $15-25$ vuotta & 79 & 43 \\
\hline yli 25 vuotta & 34 & 19 \\
\hline \multicolumn{3}{|l|}{ Työsuhde } \\
\hline vakinainen & 177 & 97 \\
\hline määräaikainen & 6 & 3 \\
\hline \multicolumn{3}{|l|}{ Työnantaja } \\
\hline yksityinen lääkäriasema & 93 & 51 \\
\hline terveyskeskuksen työterveysyksikkö & 41 & 23 \\
\hline yrityksen oma työterveysasema & 22 & 12 \\
\hline $\begin{array}{l}\text { useamman yrityksen yhteinen } \\
\text { työterveysasema }\end{array}$ & 20 & 11 \\
\hline muu (esim. valtio) & 6 & 3 \\
\hline \multicolumn{3}{|l|}{ Työaikamuoto } \\
\hline kokoaikainen & 164 & 91 \\
\hline osa-aikainen & 16 & 9 \\
\hline \multicolumn{3}{|l|}{ Asiakkaiden määrä } \\
\hline alle 600 asiakasta & 37 & 21 \\
\hline 600-900 asiakasta & 58 & 32 \\
\hline 901-1200 asiakasta & 40 & 22 \\
\hline yli 1200 asiakasta & 44 & 25 \\
\hline
\end{tabular}


Taulukko 2. Työterveyshoitajien työpaikkakulttuuri

\begin{tabular}{|c|c|c|c|}
\hline Työpaikkakulttuuri (väittämien Ikm) & Mediaani & $Q_{1}, Q_{3}$ & Cronbachin $\alpha$ \\
\hline Stressi (36) & 2.75 & $2.31,3.47$ & 0.95 \\
\hline Työmäärä (5) & 4.60 & $3.80,5.50$ & 0.93 \\
\hline Riittämätön valmistautuminen (3) & 3.00 & $2.67,4.00$ & 0.81 \\
\hline Kommunikaation ja tuen puute (5) & 2.80 & $2.20,3.80$ & 0.80 \\
\hline Työyhteisön tuen puute (3) & 2.67 & $2.00,4.00$ & 0.89 \\
\hline Työn ja sosiaalisen elämän yhteensovittaminen (4) & 2.50 & $1.81,3.50$ & 0.84 \\
\hline Urakehitys (4) & 2.50 & $1.50,3.25$ & 0.74 \\
\hline Kliininen työympäristö (4) & 2.25 & $1.50,3.00$ & 0.77 \\
\hline Hoitoon liittyvä epävarmuus (4) & 2.00 & $1.50,2.75$ & 0.77 \\
\hline Ristiriidat toisten hoitajien kanssa (4) & 2.00 & $1.50,2.75$ & 0.69 \\
\hline Työtyytyväisyys (18) & 4.56 & $3.94,5.28$ & 0.89 \\
\hline Henkilökohtainen tyytyväisyys (5) & 5.20 & $4.60,5.80$ & 0.81 \\
\hline Tyytyväisyys kouluttautumismahdollisuuksiin (3) & 5.00 & $3.33,6.00$ & 0.96 \\
\hline Ammatillinen tyytyväisyys (5) & 4.80 & $4.15,5.60$ & 0.81 \\
\hline Tyytyväisyys palkkaan ja mahdollisuuksiin (5) & 3.80 & $3.00,4.80$ & 0.81 \\
\hline Työympäristö (24) & 4.50 & $3.63,5.25$ & 0.93 \\
\hline Lääkäri-hoitajayhteistyö (3) & 5.33 & $4.00,6.00$ & 0.90 \\
\hline Aikeet vaihtaa työpaikkaa* (3) & 5.17 & $3.00,6.92$ & 0.96 \\
\hline Hoitotyön johtaminen (7) & 4.71 & $4.00,5.29$ & 0.80 \\
\hline Sitoutuminen työpaikkaan (3) & 4.33 & $3.67,5.67$ & 0.74 \\
\hline Työn hallinta (4) & 4.00 & $2.75,5.00$ & 0.90 \\
\hline Henkilökunnan ja muiden resurssien riittävyys (4) & 3.50 & $2.56,5.00$ & 0.85 \\
\hline
\end{tabular}

* Huom. Analyysissa väittämän suunta käännetty. Suuri luku osoittaa suurempaa ja pieni luku pienempää aikomusta pysyä nykyisessä työssä.

Parhaiten työympäristössä koettiin toteutuvan lääkäri-hoitaja-yhteistyön, huonoimmaksi koettiin henkilökunnan ja muiden resurssien riittävyys. (Taulukko 2.)

Kokonaisvaltaisen stressin kokemukseen oli taustamuuttujista tilastollisesti merkitsevästi yhteydessä työterveyshoitajien koulutustaso (Kruskal-Wallis $\mathrm{H}=6.7, \mathrm{p}=0.036$ ) ja työterveysasiakkaiden määrä (Kruskal-Wallis $\mathrm{H}=10.2, \mathrm{p}=0.017$ ). Eniten kokonaisvaltaista stressiä kokivat ammattikorkeakoulutaustaiset työterveyshoitajat sekä työterveyshoitajat, joilla työterveysasiakkaita oli 901-1200. Vähiten kokonaisvaltaista stressiä kokivat työterveyshoitajat, joilla työterveysasiakkaita oli alle 600. Stressin osa-alueisiin taustamuuttujista olivat tilastollisesti merkitsevästi yhteydessä koulutustaso, työkokemus nykyisessä työpaikassa, työnantaja sekä työterveysasiakkaiden määrä. (Taulukko 3.)
Työterveyshoitajien työtyytyväisyyteen oli taustamuuttujista tilastollisesti merkitsevästi yhteydessä työkokemus nykyisessä työpaikassa (Kruskal-Wallis $\mathrm{H}=8.7, \mathrm{p}=0.013$ ) sekä työkokemus työterveyshoitajana (Anova, $\mathrm{F}=4.504, \mathrm{p}=0.013$ ). Tyytyväisimpiä olivat yli 15 vuotta nykyisessä työpaikassa työskennelleet ja yli 25-vuotta työterveyshoitajana olleet. Tyytymättömimpiä olivat alle viisi vuotta nykyisessä työpaikassa työskennelleet sekä alle 15 vuotta työterveyshoitajana olleet. Työtyytyväisyyden osa-alueisiin taustamuuttujista olivat tilastollisesti merkitsevästi yhteydessä työkokemus nykyisessä työpaikassa, työkokemus työterveyshoitajana, työnantaja sekä työterveysasiakkaiden määrä. (Taulukko 4.)

Työterveyshoitajien kokemukseen työympäristöstä oli taustamuuttujista tilastollisesti merkitsevästi yhteydessä työkokemus nykyi- 


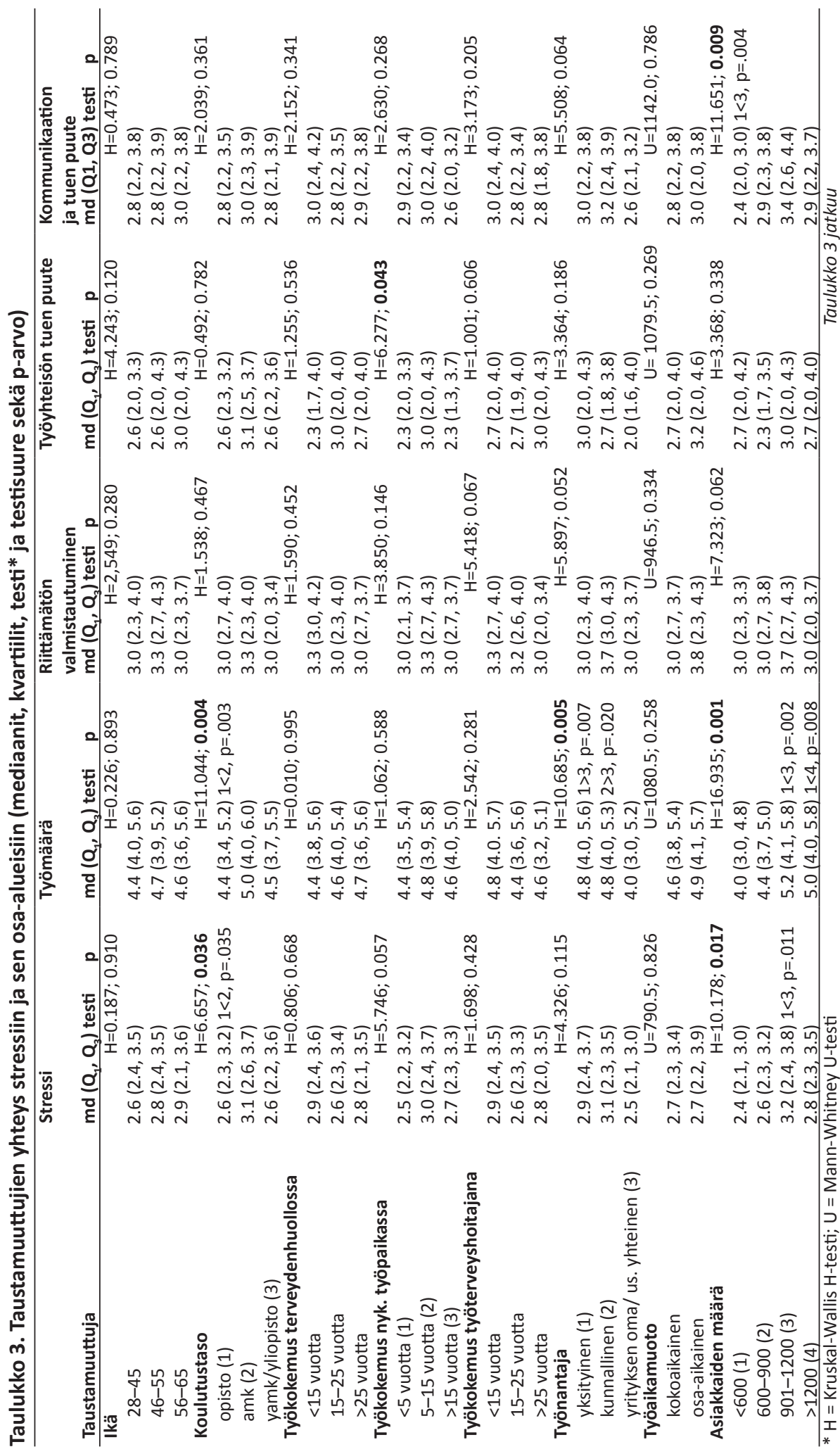




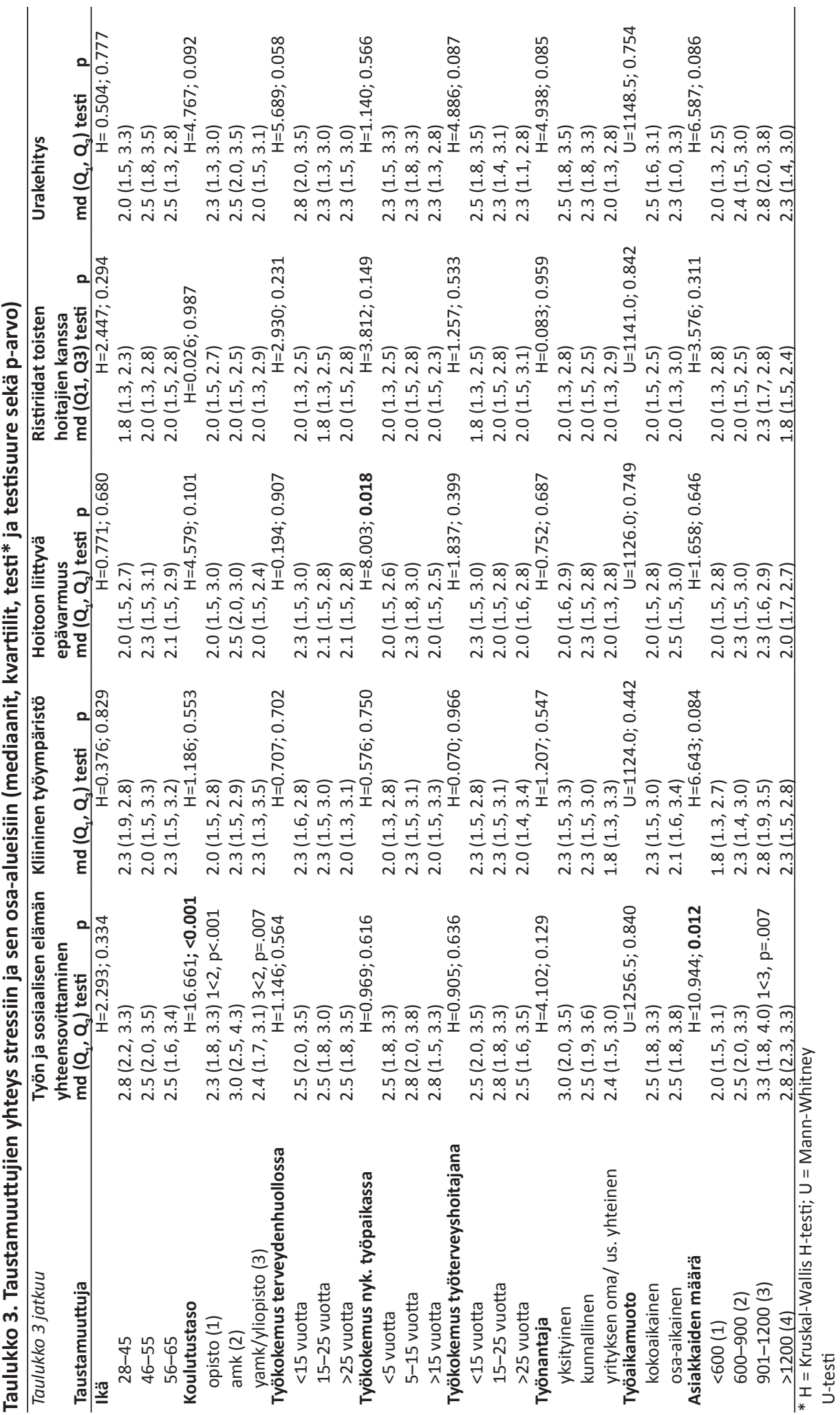




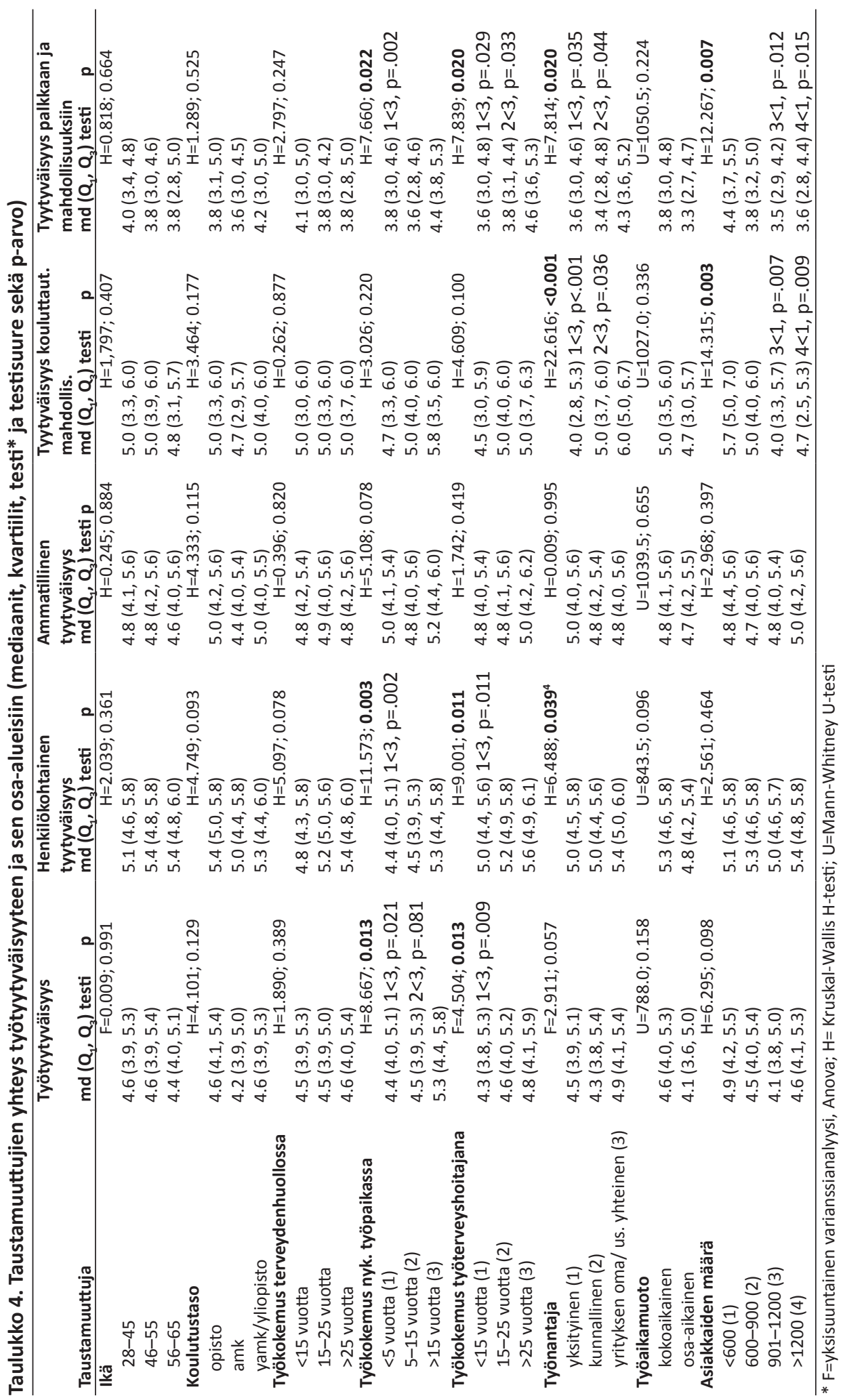




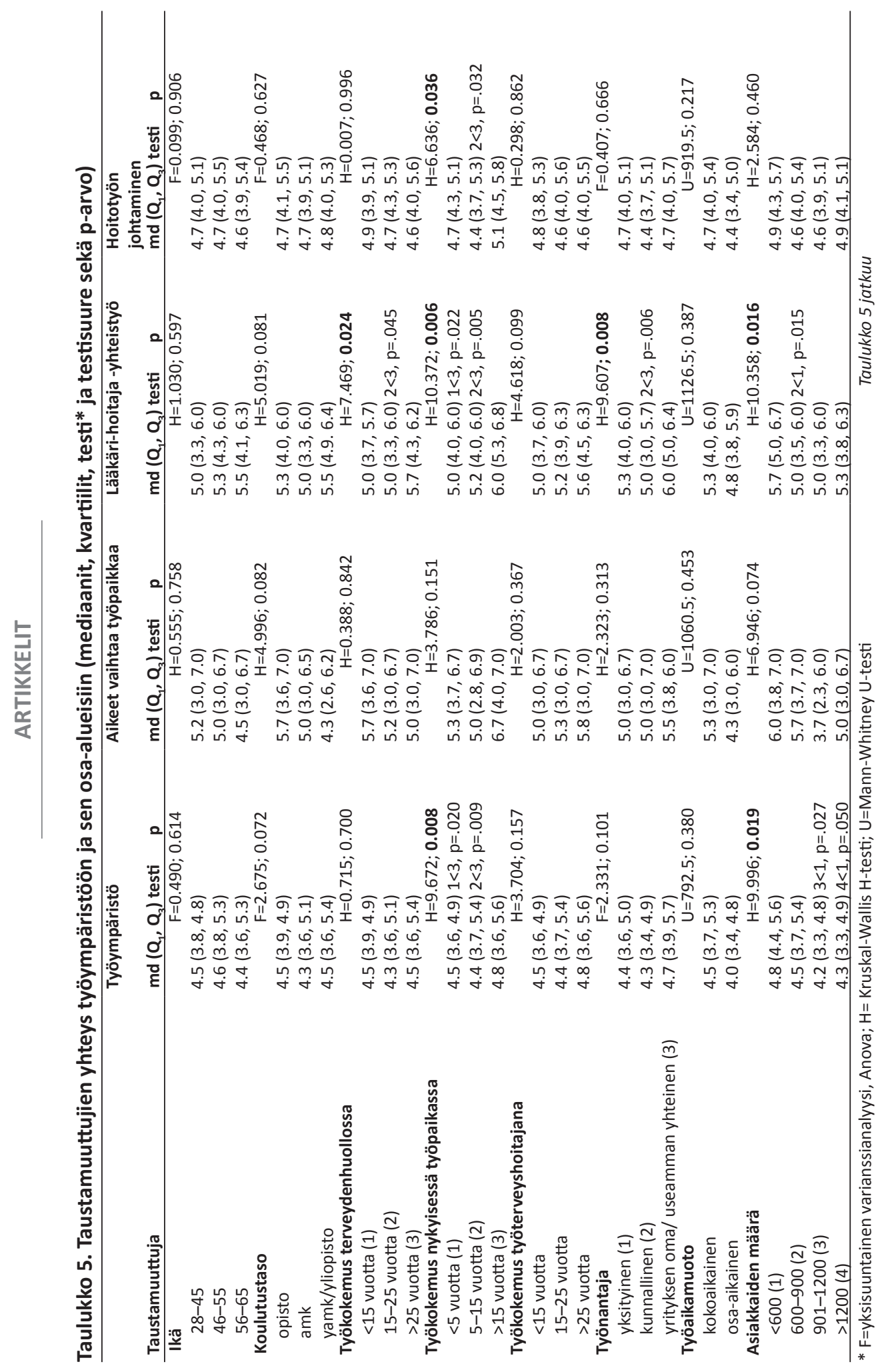




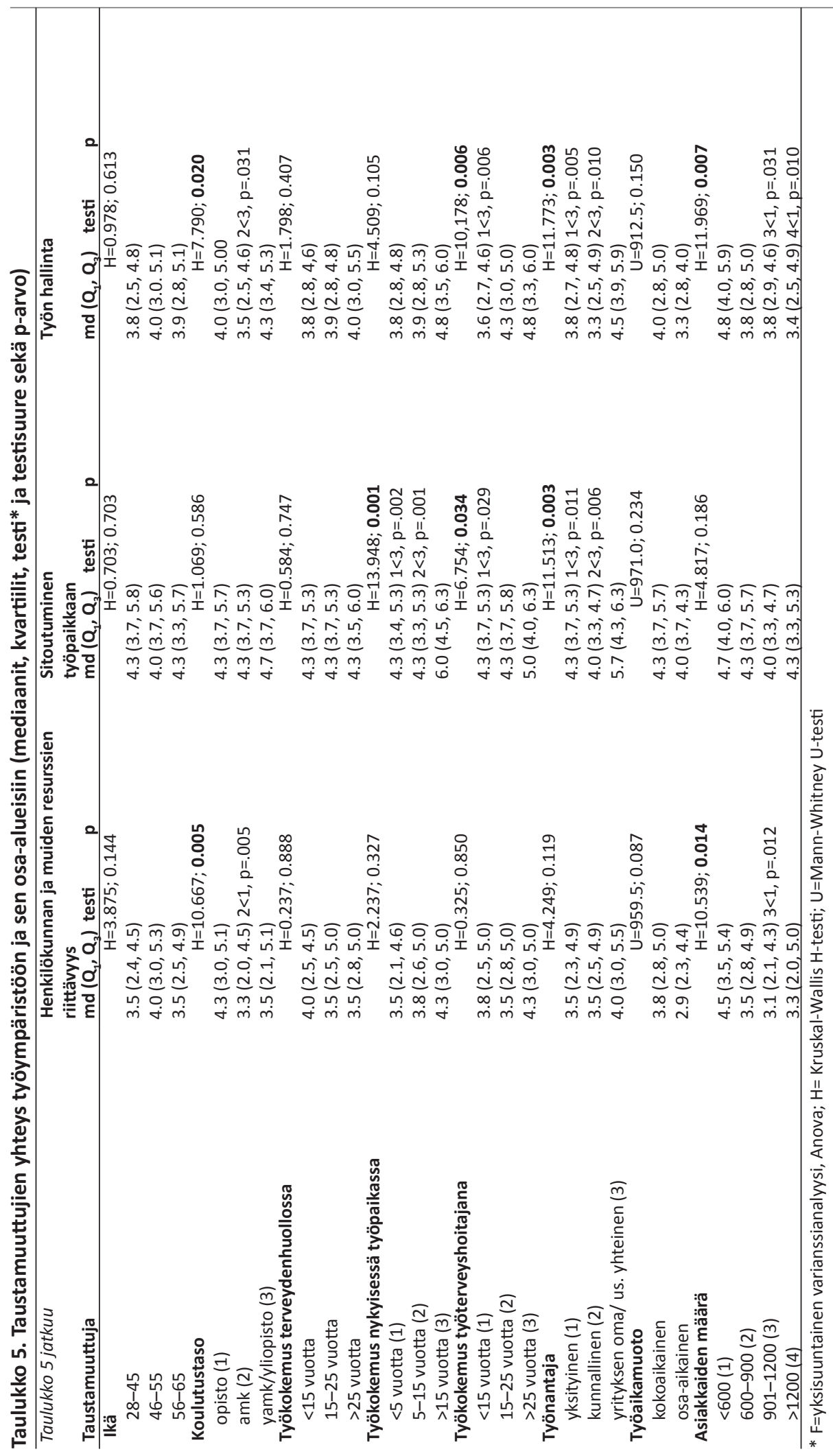


sessä työpaikassa (Kruskal-Wallis $\mathrm{H}=9.7$; $\mathrm{p}=0.008$ ) ja työterveysasiakkaiden määrä (Kruskal-Wallis $\mathrm{H}=10.0$, $\mathrm{p}=0.019$ ). Työterveyshoitajat, joilla oli työkokemusta nykyisessä työpaikassa yli 15 vuotta, pitivät työympäristöään myönteisempänä verrattuna niihin työterveyshoitajiin, joilla työkokemusta oli 5-15 vuotta tai alle viisi vuotta. Työympäristönsä myönteisimmin kokivat työterveyshoitajat, joilla työterveysasiakkaita oli alle 600 ja negatiivisimmin ne, joilla työterveysasiakkaita oli 901-1200. Työympäristön osa-alueisiin taustamuuttujista olivat tilastollisesti merkitsevästi yhteydessä koulutustaso, työkokemus terveydenhuollossa, työkokemus nykyisessä työpaikassa, työnantaja sekä työterveysasiakkaiden määrä. (Taulukko 5.)

\section{Affektiivisen organisaatioon sitoutumisen ja työpaikkakulttuurin yhteys}

Työterveyshoitajat olivat jokseenkin affektiivisesti sitoutuneita työhönsä (md=4.17, $Q_{1}=3.04$, $\mathrm{Q}_{3}=5.33$ ). Affektiivinen sitoutuminen organisaatioon oli tilastollisesti merkitsevästi yhteydessä työpaikkakulttuuriin ja kaikkiin muihin sen osa-alueisiin paitsi stressin osa-alueeseen riittämätön valmistautuminen. Voimakkaimmin affektiivisen sitoutumisen kanssa korreloi kokemus työympäristöstä ja heikoimmin kokemus stressistä. Työympäristön ja sen osa-alueiden sekä affektiivisen sitoutumisen välillä vallitsi positiivinen riippuvuus, samoin työtyytyväisyyden osa-alueiden ja affektiivisen organisaatioon sitoutumisen välillä. Stressin osaalueiden ja affektiivisen sitoutumisen välinen riippuvuus oli negatiivinen. (Taulukko 6.)

Taulukko 6. Työpaikkakulttuurin osa-alueiden ja affektiivisen sitoutumisen välinen korrelaatio

\begin{tabular}{|c|c|c|}
\hline Työpaikkakulttuuri & $\begin{array}{l}\text { Affektiivinen } \\
\text { sitoutuminen }\end{array}$ & p-arvo \\
\hline Stressi & -.33 & $<0.001$ \\
\hline Työyhteisön tuen puute & -.39 & $<0.001$ \\
\hline Kommunikaation ja tuen puute & -.33 & $<0.001$ \\
\hline Kliininen ympäristö & -.31 & $<0.001$ \\
\hline Urakehitys & -.32 & $<0.001$ \\
\hline Hoitoon liittyvä epävarmuus & -.29 & $<0.001$ \\
\hline Ristiriidat toisten hoitajien kanssa & -.27 & $<0.001$ \\
\hline Työmäärä & -.23 & 0.002 \\
\hline Työn ja sosiaalisen elämän yhteensovittaminen & -.16 & 0.035 \\
\hline Riittämätön valmistautuminen & -.14 & 0.057 \\
\hline Työtyytyväisyys & $.54^{1}$ & $<0.001$ \\
\hline Ammatillinen tyytyväisyys & .50 & $<0.001$ \\
\hline Tyytyväisyys kouluttautumismahdollisuuksiin & .47 & $<0.001$ \\
\hline Tyytyväisyys palkkaan ja mahdollisuuksiin & .44 & $<0.001$ \\
\hline Henkilökohtainen tyytyväisyys & .36 & $<0.001$ \\
\hline Työympäristö & $.68^{1}$ & $<0.001$ \\
\hline Sitoutuminen työpaikkaan & .70 & $<0.001$ \\
\hline Aikeet vaihtaa työpaikkaa² & .58 & $<0.001$ \\
\hline Työn hallinta & .55 & $<0.001$ \\
\hline Hoitotyön johtaminen & $.54^{1}$ & $<0.001$ \\
\hline Lääkäri-hoitajayhteistyö & .45 & $<0.001$ \\
\hline Henkilökunnan ja muiden resurssien riittävyys & .32 & $<0.001$ \\
\hline
\end{tabular}




\section{Tulosten tarkastelu}

Työterveyshoitajat kokivat työpaikkakulttuurinsa kokonaisuudessaan lievästi myönteiseksi. Tulos on vastaavanlainen kuin samalla mittarilla muissa terveydenhuollon konteksteissa Suomessa toteutetussa tutkimuksessa (esim. Hahtela 2015; Kurjenluoma ym. 2017; Sannemann ym. 2017). Stressiä työterveyshoitajat kokivat jonkin verran. Eniten stressiä työterveyshoitajille aiheutti työmäärä (ks. myös Hahtela 2015; Kurjenluoma ym. 2017; Sannemann ym. 2017). Eniten stressiä työmäärästä kokivat ammattikorkeakoulututkinnon suorittaneet. Muiden hoitajien tavoin vähiten stressiä työterveyshoitajat kokivat ristiriidoista toisten hoitajien kanssa (Hahtela 2015; Sannemann ym. 2017) sekä hoitoon liittyvästä epävarmuudesta (Sannemann ym. 2017). Työhönsä työterveyshoitajat olivat muiden hoitajien (Kurjenluoma ym. 2017; Sannemann ym. 2017) lailla jokseenkin tyytyväisiä. Tyytyväisyys oli korkein henkilökohtaisella tasolla, tyytymättömimpiä oltiin palkkaan ja mahdollisuuksiin (ks. myös Hahtela 2015; Kurjenluoma ym. 2017; Sannemann ym. 2017). Työympäristönsä työterveyshoitajat kokivat jokseenkin myönteisenä. Työympäristössä työterveyshoitajat kokivat toteutuvan parhaiten aiempien tutkimusten lailla lääkäri-hoitaja-yhteistyön (Hahtela 2015; Sannemann ym. 2017), huonoimmaksi koettiin henkilökunnan ja muiden resurssien riittävyys (ks. Sannemann ym. 2017). Poiketen useista muista työpaikkakulttuuria terveydenhuollon eri konteksteissa kuvaavista tutkimuksista (Hahtela 2015; Kurjenluoma ym. 2017; Sannemann ym. 2017), tässä tutkimuksessa hoitajien ikä ei ollut yhteydessä työpaikkakulttuuriin.

Työterveyshoitajat, joilla oli omia asiakkaita 901-1200, olivat kautta linjan stressaantuneimpia, tyytymättömimpiä ja kokivat työympäristönsä heikoimmaksi. He kokivat eniten kokonaisvaltaista stressiä, kommunikaation ja tuen puutteen sekä työn ja sosiaalisen elämän yhteensovittamisen aiheuttamaa stressiä. Tulokset ovat samansuuntaiset kuin koko työterveyshuoltohenkilöstöä koskevassa tutkimuksessa (Moses ym. 2016), jossa henkilöasiakkaiden määrän kasvu lisäsi työntekijöiden stressiä sekä heikensi työ- ja perhe-elämän tasapainoa. Vaikka muun työterveyshenkilöstön määrä Suomessa on lisääntynyt, niin terveydenhoitajien toimien määrä työterveyshuollossa ei ole muuttunut merkitsevästi viimeisen 10 vuoden aikana omien asiakkaiden määrän lisääntymisestä huolimatta. (Lappalainen ym. 2016.)

Nykyisessä työpaikassa 5-15 vuotta työskennelleet olivat yleisesti ottaen stressaantuneimpia, tyytymättömimpiä työhönsä sekä kokivat työympäristönsä negatiivisemmin. He kokivat enemmän työyhteisön tuen puutetta ja hoitoon liittyvää epävarmuutta kuin ne, jotka olivat työskennelleet nykyisessä työpaikassa alle viisi tai yli 15 vuotta. Yli 15 vuotta nykyisessä työpaikassa työskennelleet olivat tyytyväisimpiä työhönsä ja kokivat työympäristönsä myönteisimmin. Tulokset ovat samansuuntaiset aiempien tutkimusten (esim. Kurjenluoma ym. 2017) kanssa, joissa 5-9 vuotta nykyisessä työpaikassa työskennelleet olivat stressaantuneempia ja tyytymättömämpiä kuin lyhyemmän tai pidemmän aikaa työskennelleet.

Yrityksen omassa tai useamman yrityksen yhteisessä työterveysyksikössä työskentelevät työterveyshoitajat kokivat vähemmän stressiä, olivat kautta linjan tyytyväisempiä työhönsä sekä kokivat työympäristöönsä myönteisempänä verrattuna yksityisellä ja kunnallisella sektorilla työskenteleviin. Tämä saattaa johtua siitä, että yritysten omat tai useamman yrityksen yhteiset työterveysyksiköt ovat monesti pieniä yksiköitä ja niissä henkilöasiakkaita työterveyshoitajaa kohden on vähemmän (Lappalainen ym. 2016).

Työterveyshoitajien kokemus työpaikkakulttuurista ja affektiivinen sitoutuminen organisaatioon olivat yhteydessä toisiinsa. Työterveyshoitajien kokeman stressin ja affektiivisen sitoutumisen välillä yhteys oli negatiivinen ja voimakkuudeltaan kohtalainen tai heikko. Tulokset viittaavat siihen, että työter- 
veyshoitajien stressin lisääntyminen on yhteydessä heikkenevään affektiiviseen organisaatioon sitoutumiseen. Vastaavanlaisia tuloksia koetun stressin ja affektiivisen sitoutumisen välisestä yhteydestä on todettu aiemmissa tutkimuksissa (Meyer ym. 2002; Turunen 2012). Tässä tutkimuksessa myös kaikilla muilla stressin osa-alueilla ja affektiivisella sitoutumisella oli negatiivinen yhteys, lukuun ottamatta riittämätöntä valmistautumista.

Työterveyshoitajien työtyytyväisyyden ja affektiivisen sitoutumisen välillä yhteys oli positiivinen ja voimakkuudeltaan voimakkaasta kohtalaiseen. Tulokset viittaavat siihen, että työterveyshoitajien korkea työtyytyväisyys on yhteydessä heidän voimakkaaseen affektiiviseen sitoutumiseensa organisaatioon. Tulokset ovat linjassa aiempien (Meyer ym. 2002; Ensio ym. 2014) tutkimusten kanssa. Samoin kokemuksella työympäristöstä ja affektiivisella sitoutumisella oli positiivinen yhteys, voimakkuudeltaan voimakkaasta kohtalaiseen. Tulokset viittaavat siihen, että työterveyshoitajien myönteiset kokemukset työympäristöstä ovat yhteydessä heidän voimakkaaseen affektiiviseen sitoutumiseensa organisaatioon (ks. Lu ym. 2012).

\section{Tutkimuksen heikkoudet ja vahvuudet}

Aineiston keruumenetelmänä oli sähköinen kysely. Huolimatta kuukauden vastausajasta ja kolmesta muistutuskirjeestä vastausprosentti jäi matalaksi (15 \%). Riski alhaisesta vastausprosentista tiedostettiin aineistonkeruun valinnan yhteydessä (Baruch \& Holtom 2008). Vastausprosentti olisi saattanut olla korkeampi, jos tutkimukseen olisi kutsuttu muulla tavalla kuin sähköpostitse (Bandilla ym. 2012). Kadon suuruuteen on saattanut vaikuttaa kyselylomakkeen pituus, tekniset ongelmat kyselylomakkeen lähettämisessä sekä muut samanaikaisesti välitetyt viestit liiton jäsenille. Vaikka vastaajina oli 187 työssäkäyvää työterveyshoitajaa, ei voida olla varmoja siitä, miten hyvin he edustavat koko kohdejoukkoa.
Tutkimuksessa käytettiin kansainvälisiä mittareita, jotka molemmat oli kaksoiskäännetty suomen kielelle. Mittareiden Cronbachin alfa-arvot työpaikkakulttuuria mittaavan NCImittarin osalta vaihtelivat välillä $0.69-0.96$ ja affektiivista organisaatioon sitoutumista mittaavan ACS-mittarin osalta arvo oli 0.88 . Molempien mittareiden alfa-arvojen todettiin olevan sisäisesti johdonmukaisia (Tavakol \& Dennick 2011). Verrattaessa Cronbachin alfaarvoja aiempiin tutkimuksiin, arvot olivat saman suuntaisia (LoBiondo-Wood \& Haber 2010).

\section{Johtopäätökset ja jatkotutkimusehdotukset}

Työterveyshoitajien kokemukset työterveyshuollon työpaikkakulttuurista ovat linjassa aiempien Suomessa eri terveydenhuollon konteksteissa toteutettujen työpaikkakulttuurin tutkimusten tulosten kanssa. Myönteisenä koettu työpaikkakulttuuri edistää työterveyshoitajien työssä pysymistä ja sitoutumista. Työterveyshoitajien affektiivinen sitoutuminen organisaatioon on yhteydessä työterveyshoitajien kokemukseen työpaikkakulttuurista ja lähes kaikkiin sen osa-alueisiin. Voimakkaimmin affektiivinen sitoutuminen on yhteydessä työterveyshoitajien kokemukseen työympäristöstä. Hoitajien affektiivista sitoutumista voidaan vahvistaa vaikuttamalla työympäristötekijöihin niin, että työterveyshoitajat kokevat työympäristönsä myönteisempänä.

Tutkimuksen perusteella kaksi työterveyshoitajaryhmää erottuu muista ollen laaja-alaisesti stressaantuneimpia sekä tyytymättömimpiä työhönsä ja työympäristöönsä. Nämä ovat työterveyshoitajat, joilla omia asiakkaita on 901-1200 sekä työterveyshoitajat, joilla työkokemusta nykyisessä työpaikassa on 5-15 vuotta. Nämä työterveyshoitajat tulisi erityisesti ottaa huomioon organisaatioissa. Heidän sitoutumisensa organisaatioon on heikointa ja he ovat muita todennäköisemmin vaihtamassa työpaikkaa tai sairastumassa työuupumukseen. Keskeistä olisi omien asiakkaiden mää- 
rän kohtuullisena pitäminen sekä työnantaman mahdollistama työnkierto.

Työterveyshoitajat, joiden työnantaja on yrityksen oma tai useamman yrityksen yhteinen työterveysyksikkö, ovat laajakirjoisesti tyytyväisimpiä työhönsä ja työympäristönsä sekä kokevat vähiten työhön liittyvää stressiä. Nämä työterveysyksiköt ovat usein pieniä yksiköitä, joissa asiakkaita työterveyshoitajaa kohden on vähemmän. Työyksiköiden koon kasvu kuntapuolen liikelaitoksien ja yksityisen puolen yritysintegraatioiden seurauksena ei välttämättä ole vaikuttanut myönteisesti työterveyshoitajien kokemukseen työpaikkakulttuuristaan. Työterveyshoitajien kokemusta työpaikkakulttuuristaan tulisi syventää jat-

\section{Kirjallisuus}

Allen, N. \& Meyer, J. P. (1990) The measurement and antecedents of affective, continuance and normative commitment to the organization. Journal of Occupational Psychology 63 (1), 1-18. https://doi.org/10.1111/j.2044-8325.1990. tb00506.x.

Bandilla, W., Couper M. P. \& Kaczmirek, L. (2012) The mode of invitation for web surveys. Survey Practice 5 (3), 237-248. https://doi.org/10.29115/SP-2012-0014.

Baruch, Y. \& Holtom, B. C. (2008) Survey response rate levels and trends in organizational research. Human Relations 61 (8), 1139-1160. https://doi.org/10.1177/0018726708094863.

Burns, N. \& Grove, S. K. (1997) The Practice of Nursing Research: Conduct, Critique, and Utilization. 3. painos. Philadelpihia: Saunders.

Chan, Z. C.Y., Tam, W. S., Lung, M. K. Y., Wong, W. Y. \& Chau, C. W. (2013) A systematic literature review of nurse shortage and the intention to leave. Journal of Nursing Management 21 (4), 605-613. https://doi.org/10.1111/j.13652834.2012.01437.x.

Cohen, A. (1996) On the discriminant validity of the Meyer and Allen measure of organizational commitment: How does it fit with the work commitment construct? Educational and Psychological Measurement 56 (3), 494-503.

Curtis, E. A. \& Glacken, M. (2014) Job satisfaction among public health nurses: A national survey. kossa laadullisella tutkimuksella, jotta voidaan tunnistaa tarkemmin ne erityispiirteet, jotka ovat ominaisia juuri työterveyshoidon kontekstissa.

\section{Kirjoittajat}

Anne Haanperä, TtM, palveluneuvoja, Suomen Terveystalo Oy:n yritysasiakaspalvelu, sähköposti: haaan@luukku.com Tarja Suominen, THT, professori, Tampereen yliopisto, sähköposti: tarja.suominen@tuni.fi Mervi Roos, TtM, väitöskirjatutkija, yliopisto-opettaja, Tampereen yliopisto, sähköposti: mervi.roos@tuni.fi

Journal of Nursing Management 22 (5), 653-663. https://doi.org/10.1111/jonm.12026.

Ensio, A., Kinnunen, J., Lammintakanen, J. \& Suomalainen, S. (2014) Työtyytyväisyys meillä ja muualla. Teoksessa I. Ranta \& E. Tillander (toim.) Työhyvinvoinnin keinot. Hoitotyön vuosikirja 2014. Porvoo: Bookwell, 61-75.

Glisson, C. \& James, L. R. (2002) The cross-level effects of culture and climate in human service teams. Journal of Organizational Behavior 23 (6), 767-794. https://doi.org/10.1002/job.162.

Hahtela, N. (2015) Workplace Culture in Primary Health Care. The connection to nursing-sensitive outcome. Tampere: Tampere University Press.

Hemmelgarn, A., Glisson, C. \& James, L. (2006) Organizational culture and climate: Implications for services and interventions research. Clinical Psychology: Science and Practice 13 (1), 73-89. https://doi.org/10.1111/j.14682850.2006.00008.x.

Kela (2017) Tilastokatsaus 12.4.2017. Työnantajien omilta työterveysasemilta saa työterveyshuoltopalvelut enää joka kymmenes työntekijä. [online]. $<$ https://helda.helsinki.fi/bitstream/handle/10138/179350/Tyonantajien_omilta_tyoterveysasemilta_saa_tyoterveyshuoltopalvelut enaa_vain_joka_kymmenes_tyontekija.pdf?sequence $=4 \&$ isAllowed $=y>$. Luettu 13.2.2020. 
Kurjenluoma, K., Rantanen, A., McCormack, B., Slater, P., Hahtela, N. \& Suominen, T. (2017) Workplace culture in psychiatric nursing described by nurses. Scandinavian Journal of Caring Sciences 31 (4), 1048-1058. https://doi.org/10.1111/scs.12430.

Kyrönlahti, E. (2005) Työterveyshuollossa työskentelevän terveydenhoitajan ammatillinen osaaminen. Tampere: Tampere University Press.

Lappalainen, K., Aminoff, M., Hakulinen, H., Hirvonen, M., Räsänen, K., Sauni, R. \& Stengård, J. (2016) Työterveyshuolto Suomessa vuonna 2015 ja kehitystrendi 2000-2015. Työterveyslaitos. [online]. <URL: https://www.julkari.fi/ handle/10024/131293>. Luettu 31.3.2020.

LoBiondo-Wood, G. \& Haber J. (2010) Reliability and validity. Teoksessa G. LoBiondo-Wood \& J. Haber (toim.) Nursing research, methods and critical appraisal for evidence-based practice.7. painos. St Louis, Missouri: Mosby Elsevier, 285308.

Lu, H., Barriball, K. L., Zhang, X. \& While, A. E. (2012) Job satisfaction among hospital nurses revisited: a systematic review. International Journal of Nursing Studies 49 (8), 1017-1038. https://doi.org/10.1016/j.ijnurstu.2011.11.009.

Manley, K., Sanders, K., Cardiff, S. \& Webster, J. (2011) Effective workplace culture: The attributes, enabling factors and consequences of a new concept. International Practice Development Journal 1 (2), 1-29.

Meyer, J. P., Allen, N. J. \& Smith, C. A. (1993) Commitment to organizations and occupations: Extension and test of a three-component conceptualization. Journal of Applied Psychology 78 (4), 538-551.

https://doi.org/10.1037/0021-9010.78.4.538.

Meyer, J. P. \& Allen, N. J. (2004) TCM Employee Commitment Survey Academic Users Guide. Revised Version (Meyer, Allen, \& Smith, 1993). Tutkimusmittari. [online]. <https://www.employeecommitment.com/TCM-Employee-Commitment-Survey-Academic-Package-2004.pdf>. Luettu 13.2.2020.

Meyer, J. P., Stanley, D. J., Herscovitch, L. \& Topolnytsky, L. (2002) Affective, continuance and normative commitment to the organization: A metaanalyses of antecedents, correlates and consequences. Journal of Vocational Behaviour 61 (1), 20-52. https://doi.org/10.1006/jvbe.2001.1842. Miedaner, F., Kuntz, L., Enke, C., Roth, B. \& Nitzsche,
A. (2018) Exploring the differential impact of individual and organizational factors on organizational commitment of physicians and nurses. BMC Health Services Research 18 (1), 180. https://doi.org/10.1186/s12913-018-2977-1.

Moses, E., Walters, K. M. \& Fisher, G. G. (2016) What factors are associated with occupational health office staffing, job stress and job satisfaction? Journal of Occupational and Environment Medicine 58 (6), 567-574.

https://doi.org/10.1097/JOM.0000000000000741. Naumanen-Tuomela, P. (2001) Työterveyshoitajan asiantuntijuus työikäisten terveydenedistämistyössä muuttuvassa yhteiskunnassa. Kuopio: Kuopion yliopisto. Kuopion yliopiston julkaisuja: Yhteiskuntatieteet.

Ruokolainen, M. (2011) Do organizational and job-related factors relate to organizational commitment? Jyväskylä: Jyväskylän yliopisto. Jyväskylä Studies in Education, Psychology and Social Research 428.

Sakowski, P. (2012) Job satisfaction of occupational medicine nurses in Poland. International Journal of Occupational Medicine and Environmental Health 25 (1), 51-58. https://doi.org/10.2478/s13382-012-0006-x.

Sannemann, H., Roos, M., McCormack, B., Slater, P. \& Suominen, T. (2017) Terveysasemien työpaikkakulttuuri omahoitajien arvioimana. Tutkiva Hoitotyö 15 (3), 20-31.

Schein, E. H. (2010) Organizational culture and leadership. 4. painos. San Francisco: Jossey-Bass. Shirey, M. R. (2009) Authentic leadership, organizational culture and healthy work environments. Critical Care Nursing Quarterly 32 (3), 189-198. https://doi.org/10.1097/CNQ.0b013e3181ab91db.

Simola, A. (2001) Työterveyshuolto-organisaation toiminta, sen henkilöstön henkinen hyvinvointi ja toiminnan tuloksellisuus. Jyväskylä: Jyväskylän yliopisto. Jyväskylä Studies in Education, Psychology and Social Research 188.

Slater, P. \& McCormack, B. (2006) The PersonCentred Nursing Index. Instrument. Antrim, Northern Ireland: University of Ulster.

Slater, P., McCormack, B. \& Bunting, B. (2009) The development and pilot testing of an instrument to measure nurses' working environment: The Nursing Context Index. Worldviews of Evidence-Based Nursing 6 (3), 173-182. https://doi.org/10.1111/j.17416787.2009.00159.x. 
Tavakol, M. \& Dennick R. (2011) Making sense of Cronbach's alpha. International Journal of Medical Education 2, 53-55. https://doi.org/10.5116/ ijme.4dfb.8dfd.

TENK (2012) Eettinen ennakkoarviointi ihmistieteissä. [online]. <http://www.tenk.fi/fi/eettinen-ennakkoarviointi-ihmistieteissa>. Luettu 13.2.2020.
Turunen, T. (2012) Työorientaatiot muutoksessa? Suomalaisten palkansaajien työhön ja organisaatioon sitoutuminen sekä työhön kohdistuvat odotukset eurooppalaisessa vertailussa. Helsinki: Helsingin yliopisto. Sosiaalitieteiden laitoksen julkaisuja 2012:4. 


\section{ENGLISH SUMMTARY}

Anne Haanperä, Tarja Suominen \& Mervi Roos

The workplace culture of occupational health care nurses

This article describes the workplace culture of occupational health care nurses. Data were collected using an electronic questionnaire. The respondents were nurses who worked in occupational health care units ( $\mathrm{n}=187)$. The questionnaire included background questions and employed both the Nursing Context Index instrument and the Affective Commitment Scale. Both of these instruments consisted of statements that the respondents evaluated with a seven-point Likert scale. The data were analysed by statistical methods. Occupational health care nurses described their workplace culture in a slightly positive way. They experienced some stress, with the workload seen as a major source. They were quite satisfied with their work, being most satisfied on a person- al level and least satisfied with their pay and prospects. The nurses evaluated their practice environment in slightly positive terms, with the doctor-nurse relationship featuring as the most appreciated element of their work. The most negative element noted was inadequate staff resources. Occupational health care nurses with 901-1200 clients and 5-15 years' work experience in their present workplace emerged as being more stressed and less satisfied with their work and work environment compared to the other respondent groups. They were also less affectively committed to their workplace. The study concludes that this group should be given particular attention within their organisation. 